\title{
Analysis of Knee Joint Motion in Tennis Flat Serve Using Low-Cost Technological Approach
}

\author{
F. Sgrò ${ }^{\mathrm{a}}$, P. Mango, S. Nicolosi ${ }^{\mathrm{b}}$, R. Schembri, M. Lipoma ${ }^{\mathrm{c}}$ \\ Engineering, Architecture and Physical Activity Science Faculty \\ University "Kore" of Enna \\ Enna, Italy \\ afrancesco.sgro@unikore.it, ${ }^{\mathrm{b}}$ simona.nicolosi@unikore.it, ${ }^{\mathrm{c}}$ mario.lipoma@unikore.it
}

\begin{abstract}
Tennis serve is a closed-skill motion influenced by the kinematic chain concept. An important role on the final performance is surely linked to the knee joint motion, although only few studies addressed lower-limb influence. In this work we propose a study about the proprioceptive angle size of knee joint in the first flat serve produced by tennis players of different performance levels. Twelve subjects involved in the study are divided in three groups using the ITN classification code: beginner, intermediate and advanced players. A simple biomechanical model of lower limb was proposed to study the knee joint motion. Three flat serves were recorded using three synchronized cams. A specific algorithm was developed to obtain the maximum flexion value of front knee using coordinates of lower-limb joints. Speed of impact $\left(S_{B}\right)$ and height of impact $\left(\mathrm{H}_{\mathrm{B}}\right)$ were also evaluated to compare results with previous works and to assess the tennis players' performance. Results showed a statistical meaningful difference among three groups in all performance indexes. Moreover a strong correlation was found among knee motion and $S_{B}$ and $H_{B}$.
\end{abstract}

Keywords-tennis serve, sport biomechanics, sport videoanalysis, tennis playes performance assessment.

\section{INTRODUCTION}

In tennis the efficacy of serve is an important key of successful. Fast and power flat serve is the most intimidating and fearsome weapon a player can have [1]. Flat serve is very difficult closed-skilled motion where lower and upper body segments must to be coordinate [2-3]. During this action whole body have to be involved in an integrated manner in order to improve the efficacy of serve [4]. In physical activity and sport science it always called kinematic chain. Kinematic chain describes the proximal-todistal motion produced by the body segments; in tennis serve this chain origin from the plantar-flexion of feet and it end in racquet. An important performance outcome related to kinematic chain is the speed summation principle [5].

Several studies proposed kinematic analysis of tennis serve in 2D and 3D dimensions [6-12]. Most of previous studies correlated the kinematics motion analysis with several performance outcomes (e.g. ball-speed post impact, time of execution, height of impact). Tennis trainers and sport scientist agree that an efficacy flat serve is dependent by height of impact and speed post impact $[13,14]$. The most of previous studies addressed only the implication of upper-limb motion in serve efficacy while very little is known about the role of lower-limb in serve efficacy. In addition few studies addressed the influence of Ground Reaction Force (GRF) [15]. Girard and his colleagues addressed effects of lower-limb in flat tennis serve using force platform and EMG [14]. They asserted that the lowerlimb motion and coordination are directly related to athlete's skill level defined in according to ITN classification. Reid studied the implication of lower-limb action in flat serve performance of elite players. The author confirmed the need of knowledge about knee joint motion and velocity in order to improve the athletes performance and to reduce the injuries risk [16].

Moving from this consideration the aim of this study was to address the influence of front knee joint motion in tennis players of difference skill level during flat serve action. It was hypothesized a statistical meaningful difference among the performance of different group; furthermore we studied the correlation among knee flexion motion and performance indexes. Moreover we would test the efficacy of low-cost technological solution used in this work for sport biomechanical analysis.

\section{METHODS}

In following sections we described characteristics of the sample, the experimental framework used for data gathering and statistical tests used for data elaboration. Experimental sessions were realized from January to March when athletes were in pre-season period. The research proposed in this work was realized in a tennis club of Palermo.

\section{A. Subjects}

Athletes involved in this work have different performance level, based on official results and sport experience. Athletes are grouped into the following three groups based on International Tennis Number (ITN) classification parameters [14]:

1)Beginner (B) - ITN=9: tennis players with regular physical active and past presence incompetitions;

2)Intermediate (I) - ITN=6: good club tennis players who play tennis since many years;

3)Advanced Players (AP) - ITN=3: player of national level who regularly practices tennis with high intensity. 
All the players were right-handed and they produced consensus to this study.

We describe main characteristics of athletes in Table 1. Data are proposed as mean \pm standard deviation (SD).

TABLE I. ANTRPOMETRICH CHARACTERISITCS OF ATHLETES

\begin{tabular}{|l|c|c|c|}
\hline \multirow{2}{*}{} & \multicolumn{3}{|c|}{ ITN Classification } \\
\cline { 2 - 4 } & $\begin{array}{c}\text { Beginner } \\
(\boldsymbol{n}=4)\end{array}$ & $\begin{array}{c}\text { Intermediate } \\
(\boldsymbol{n}=4)\end{array}$ & $\begin{array}{c}\text { Advanced Players } \\
(\boldsymbol{n}=4)\end{array}$ \\
\hline Age & $22,00 \pm 5,39$ & $19,50 \pm 5,88$ & $26,75 \pm 1,38$ \\
\hline Height (m) & $1,73 \pm 0,03$ & $1,77 \pm 0,39$ & $1,79 \pm 0,04$ \\
\hline Weight $(\mathrm{kg})$ & $70,25 \pm 3,88$ & $69,25 \pm 4,30$ & $70,75 \pm 4,68$ \\
\hline BMI & $23,43 \pm 1,78$ & $22,14 \pm 1,95$ & $21,88 \pm 1,01$ \\
\hline $\begin{array}{l}\text { Years } \\
\text { Pactice }\end{array}$ & $0,75 \pm 0,26$ & $7,5 \pm 0,53$ & $18,75 \pm 0,88$ \\
\hline
\end{tabular}

Beginner participants didn't follow a specific conditioning program, but they played regularly for twotime at week and they had a good aerobic condition. Intermediate ones were following a specific conditioning program focused mainly tothe improvement of aerobic and anaerobic capacities. Advanced players athletes followed the same training program of intermediate but they were also involved in a specific technics-tactics training session.Training program is divided in cycle of four weeks: this method has been shown to be efficient to enhance serve velocity in advanced players [17].

\section{B. Experimental Setup}

The experiment scenario is an outdoor clay tennis court To assess the performance of athletes we built a digital platform composed by 3 sync digital cams, one radar gun and a multimedia station, as depictured in Fig. 1.

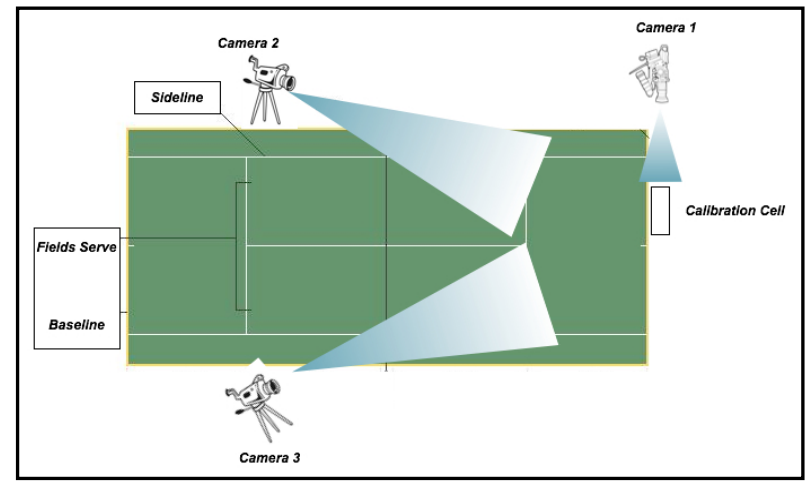

Figure 1. REPRESENTATION OF EXPERIMENTAL SCENARIO

The camera labelled "Camera 1" recorded low limb movements during the serve action. In order to asses front knee angle sizethe camera optical axis was oriented at $90^{\circ}$ to the plane of serve action; this cam orientationpermitted to reduce perspective errors, such shortening [18]. The optical axis of cams focused on a pre-defined area that was located at $20 \mathrm{~cm}$ from the midpoint of base line, in right or left direction, where we placed a specific calibration object.This object represented a "cell", with $2 \mathrm{~m}^{3}$ of volume ( $1 \mathrm{~m}$ x $2 \mathrm{~m}$ x $1 \mathrm{~m}$ ), as depictured in Fig. 2.We used this one as calibration frame in 2D analysis, but it could be used also as calibration frame for further 3D analysis [19]. The cell was recorded before the start of experimental session and the end of this one. The location position of "cell" respect the midpoint of baseline has been suggested from the tennis coach of the advanced players. The cams labelled "Camera 2" and "Camera 3" were used to record the complete tennis serve action. Camera 1 was positioned at 7 meter from the service area, while the cams number 2 and 3 were positioned at 20 meters from the service area. Video cameras were PanaSonicSD60, operating at $50 \mathrm{~Hz}$, located as represent in figure 1 . The shutter ratiowas set at 0.001 second, while the aperture was set according to the weather conditions. The experimental setup was completed with a radar (Sport Radar Speed Gun, SR3600) fixed on a tripod, 2.5 meters behind the players and in the servedirection. A laptop was used to collect data stream from three cams.

\section{Procedure and Performance Parameters}

Testing sessions were conducted on outdoor tennis court in Palermo. A tennis coach followed each testing session. Each athlete played a standardized warm-up of 10 minutes, characterized by slow run, static stretching, active joints mobilisations and submaximal run. Then they performed serves for additional 5 minutes with increasing velocity. Completed the warm-up phase, athletes had to perform flat serve from each side of court. A short period of rest, 30-45 sec, was given. The testing session ended when 3 correctly flat serves were realized for each side.

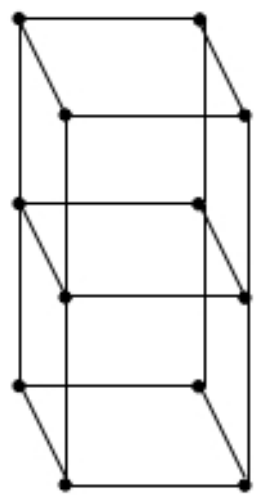

Figure 2. CALIBRATION OBJECT

In according to Girard and Brody [14,20], we considered correctly the serve when it was realized with maximum power relative to the ability of the players and land in adside service area. We chosen three shoots in according to [24]: at least three trials must be considered in the derivation of accurate and representative movement kinematic. In line with previous researches $[21,14,22]$ performance parameters chosen to evaluate serve efficiency were: parameters ball speed post-impact $\left(\mathrm{S}_{\mathrm{B}}\right)$ and impact height $\left(\mathrm{H}_{\mathrm{B}}\right)$. The first parameter was assessed by the means of radar gun while the second was obtained managing videos of camera 2 and 3 
with Skill Spector software. Last performance parameter analysed in this work was the relative front knee joint motion on sagittal plane, also called proprioceptive angle $\left(\theta_{K}\right)$. This angle was estimated using the video recorded by camera 1 , the simple biomechanical model of lower limb proposed in Fig. 3 and Skill Spector. For each athlete we fixed a marker in the hip (greater trochanter), knee (later condyle), ankle (lateral malleolus) and toes $\left(5^{\text {th }}\right.$ metatarsophalangeal joint).

The knee angle was obtained using the follow equation:

$$
\theta_{\mathrm{K}}=\theta_{\mathrm{H}}+\alpha_{\mathrm{K}}
$$

where $\theta_{\mathrm{K}}$ represents the relative angle built among femur and tibia, $\theta_{\mathrm{H}}$ represents the relative angle built among simple model of pelvis and hips and $\alpha_{K}$ the absolute angle built among tibia and longitudinal axes of sagittal plane. Parameters of (1) were defined using coordinates of joint centre obtained using Skill Spector software and several trigonometric rules. A specific Matlab algorithm was developed in order to implement the biomechanical model proposed in Fig. 3. This algorithm calculated $\theta_{\mathrm{K}}$ angle trend during the serve action using coordinates values and it returned the size at the maximum joint flexion stage. Data were filtered using $4^{\text {th }}$ order Butterwoth filter, as suggested in [23]. The knee angle considered for further analysis was the relative one, labelled $\theta_{K}{ }^{*}$, obtained using the equation $180-\theta_{\mathrm{K}}$, as depictured in Fig. 4.

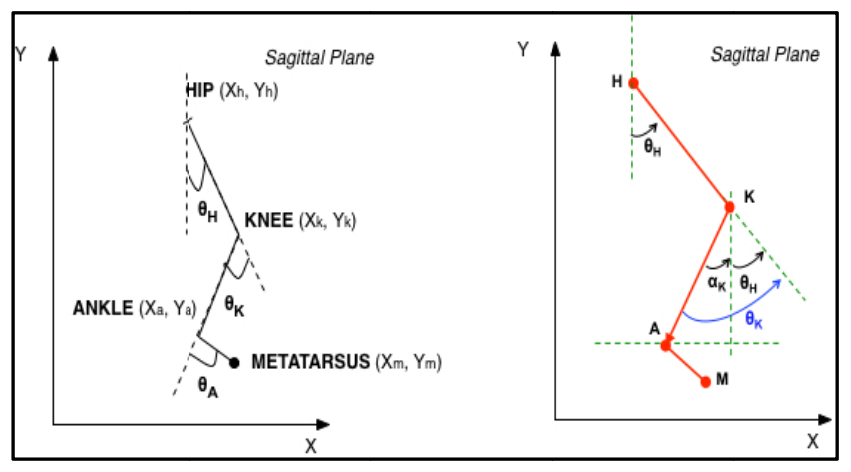

Figure 3. BIOMECHNICAL MODEL

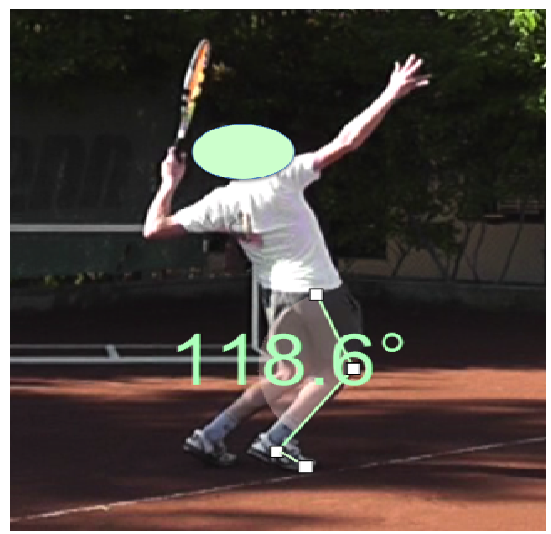

Figure 4. REPRESENTATION OF $\Theta_{\mathrm{K}}{ }^{*}$

\section{Statistical Analysis}

All analyses were conducted using SPSS version 20.0. First of all we verify the data normality using KolmogorovSmirnov test and inspecting asymmetry-kurtosis values. Then we verified the correlation among athletes' characteristics and their performance outcomes (POs), grouped by angle size, height of impact and speed postimpact. The correlation among performance outcomes was only performed. Several ANOVA tests were implemented. First, a MANCOVA (two-way ANOVA with covariate) test was implemented in order to define if the serve-side, as covariate variable, influenced the further analysis of variance among performance outcomes for ITN dependent variable. Later, MANOVA (two-way ANOVA) tests were implemented for each performance outcomes with ITN as dependent variable. Post-hoc procedures were also implemented in order to address the relation among three groups for each performance outcome. All tests were implemented setting to $\mathrm{p}<0.05$ the significance level; moreover beginners were labelled with number 1 , the intermediate with number 2 and advanced players with number 3 .

\section{RESULTS}

The statistical results are presented in follow tables. All performance outcomes are normally distribution, as stated by the Kolmogorov-Smirnov test and visual inspection of asymmetry-kurtosis values. Correlation analyses were presented in table II and III.

MANCOVA test stated that both right side that left side of court didn't affect the ANOVA test on relation performance outcomes grouped by ITN ranking. In table IV we propose results of MANOVA test in according to serve side court division.

TABLE II. CORRELATION AMONG PERFORMANCE-ATHLETES CHARACTERISITCS

\begin{tabular}{|l|c|c|c|}
\hline & $\boldsymbol{\theta}_{\boldsymbol{K}}{ }^{*}$ & $\boldsymbol{H}_{\boldsymbol{B}}$ & $\boldsymbol{S}_{\boldsymbol{B}}$ \\
\hline Age &,- 349 &, $487^{*}$ &, 376 \\
\hline Height (m) &,$- 558^{* *}$ &, $684^{*}$ &, $634^{* *}$ \\
\hline BMI &, 372 &,- 353 &,- 344 \\
\hline $\begin{array}{l}\text { Years of } \\
\text { Pactice }\end{array}$ &,$- 942^{* *}$ &, $961^{*}$ &, $969^{* *}$ \\
\hline ITN Rank &,$- 919^{* *}$ &, $925^{*}$ &, $988^{* *}$ \\
\hline
\end{tabular}


TABLE IV. MANCOVA RESULTS FOR RIGHT SIDE

\begin{tabular}{|c|c|c|c|c|}
\hline \multicolumn{5}{|c|}{ RIGHT SIDE } \\
\hline Dependent Variable & $d f$ & ITN & $\operatorname{Mean} \pm S D$ & $F$ \\
\hline \multirow{3}{*}{ Angle - Trial No. 1} & \multirow{3}{*}{2} & 1 & $132,17 \pm 8,64$ & \multirow{3}{*}{$36,08^{*}$} \\
\hline & & 2 & $126,80 \pm 5,28$ & \\
\hline & & 3 & $99,32 \pm 0,69$ & \\
\hline \multirow{3}{*}{ Angle - Trial No. 2} & \multirow{3}{*}{2} & 1 & $130,35 \pm 7,93$ & \multirow{3}{*}{$60,06^{*}$} \\
\hline & & 2 & $126,67 \pm 1,06$ & \\
\hline & & 3 & $97,62 \pm 0,39$ & \\
\hline \multirow{3}{*}{ Angle - Trial No. 3} & \multirow{3}{*}{2} & 1 & $129,82 \pm 8,65$ & \multirow{3}{*}{$39,19^{*}$} \\
\hline & & 2 & $121,92 \pm 3,15$ & \\
\hline & & 3 & $97,35 \pm 1,71$ & \\
\hline \multirow{3}{*}{$\begin{array}{c}\text { Height of impact - Trial No. } \\
1\end{array}$} & \multirow{3}{*}{2} & 1 & $2,53 \pm 0,09$ & \multirow{3}{*}{$33,44^{*}$} \\
\hline & & 2 & $2,67 \pm 0,03$ & \\
\hline & & 3 & $2,93 \pm 0,07$ & \\
\hline \multirow{3}{*}{$\begin{array}{c}\text { Height of impact- Trial No. } \\
2\end{array}$} & \multirow{3}{*}{2} & 1 & $2,56 \pm 0,07$ & \multirow{3}{*}{$64,70^{*}$} \\
\hline & & 2 & $2,65 \pm 0,01$ & \\
\hline & & 3 & $2,98 \pm 0,05$ & \\
\hline \multirow{3}{*}{$\begin{array}{c}\text { Height of impact - Trial No. } \\
3\end{array}$} & \multirow{3}{*}{2} & 1 & $2,58 \pm 0,08$ & \multirow{3}{*}{$52,28^{*}$} \\
\hline & & 2 & $2,69 \pm 0,03$ & \\
\hline & & 3 & $3,01 \pm 0,05$ & \\
\hline \multirow{3}{*}{$\begin{array}{c}\text { Speed post impact - Trial No. } \\
1\end{array}$} & \multirow{3}{*}{2} & 1 & $95,50 \pm 11,89$ & \multirow{3}{*}{$126,30^{*}$} \\
\hline & & 2 & $148,55 \pm 4,51$ & \\
\hline & & 3 & $181,80 \pm 4,64$ & \\
\hline \multirow{3}{*}{$\begin{array}{c}\text { Speed post impact- Trial No. } \\
2\end{array}$} & \multirow{3}{*}{2} & 1 & $95,40 \pm 17,26$ & \multirow{3}{*}{$60,05^{*}$} \\
\hline & & 2 & $146,10 \pm 4,71$ & \\
\hline & & 3 & $182,70 \pm 7,98$ & \\
\hline \multirow{3}{*}{$\begin{array}{c}\text { Speed post impact - Trial No. } \\
3\end{array}$} & \multirow{3}{*}{2} & 1 & $101.70 \pm 7,42$ & \multirow{3}{*}{$233,28^{*}$} \\
\hline & & 2 & $150,25 \pm 3,5$ & \\
\hline & & 3 & $188,10 \pm 5,4$ & \\
\hline
\end{tabular}

TABLE III. CORRELATION AMONG PERFORMANCE OUTCOMES

\begin{tabular}{|c|c|c|c|}
\hline & $\boldsymbol{\theta}_{\boldsymbol{K}}{ }^{*}$ & $\boldsymbol{H}_{\boldsymbol{B}}$ & $\boldsymbol{S}_{\boldsymbol{B}}$ \\
\hline $\boldsymbol{\theta}_{\boldsymbol{K}}{ }^{*}$ & &,$- 935^{* *}$ &,$- 868^{* *}$ \\
\hline $\boldsymbol{H}_{\boldsymbol{B}}$ &,$- 935^{* *}$ & &, $902^{* *}$ \\
\hline $\boldsymbol{S}_{\boldsymbol{B}}$ &,$- 868^{*}$ &, $902^{* *}$ & \\
\hline \multicolumn{4}{|c}{} \\
\hline
\end{tabular}

TABLE V. MANCOVA RESULTS FOR LEFT SIDE

\begin{tabular}{|c|c|c|c|c|}
\hline \multicolumn{5}{|c|}{$\underline{L E F T S I D E}$} \\
\hline Dependent Variable & $d f$ & $I T N$ & $M e a n \pm S D$ & $F$ \\
\hline \multirow{3}{*}{ Angle - Trial No. 1} & \multirow{3}{*}{2} & 1 & $132,70 \pm 5,87$ & \multirow{3}{*}{$57,73^{*}$} \\
\hline & & 2 & $124,25 \pm 4,88$ & \\
\hline & & 3 & $98,22 \pm 2,95$ & \\
\hline \multirow{3}{*}{ Angle - Trial No. 2} & \multirow{3}{*}{2} & 1 & $135,82 \pm 7,73$ & \multirow{3}{*}{$65,49^{*}$} \\
\hline & & 2 & $124,77 \pm 1,92$ & \\
\hline & & 3 & $96,95 \pm 3,15$ & \\
\hline \multirow{3}{*}{ Angle - Trial No. 3} & \multirow{3}{*}{2} & 1 & $131,60 \pm 9,09$ & \multirow{3}{*}{$33,41^{*}$} \\
\hline & & 2 & $123,15 \pm 3,83$ & \\
\hline & & 3 & $97,02 \pm 4,38$ & \\
\hline \multirow{3}{*}{$\begin{array}{c}\text { Height of impact - } \\
\text { Trial No. } 1\end{array}$} & \multirow{3}{*}{2} & 1 & $2,59 \pm 0,09$ & \multirow{3}{*}{$26,38^{*}$} \\
\hline & & 2 & $2,69 \pm 0,04$ & \\
\hline & & 3 & $2,97 \pm 0,07$ & \\
\hline \multirow{3}{*}{$\begin{array}{c}\text { Height of impact- } \\
\text { Trial No. } 2\end{array}$} & \multirow{3}{*}{2} & 1 & $2,58 \pm 0,06$ & \multirow{3}{*}{$55,81^{*}$} \\
\hline & & 2 & $2,65 \pm 0,05$ & \\
\hline & & 3 & $3,01 \pm 0,07$ & \\
\hline \multirow{3}{*}{$\begin{array}{c}\text { Height of impact - } \\
\text { Trial No. } 3\end{array}$} & \multirow{3}{*}{2} & 1 & $2,60 \pm 0,03$ & \multirow{3}{*}{$59,88^{*}$} \\
\hline & & 2 & $2,66 \pm 0,04$ & \\
\hline & & 3 & $3,03 \pm 0,08$ & \\
\hline \multirow{3}{*}{$\begin{array}{c}\text { Speed post impact- } \\
\text { Trial No. } 1\end{array}$} & \multirow{3}{*}{2} & 1 & $96,30 \pm 13,58$ & \multirow{3}{*}{$83,86^{*}$} \\
\hline & & 2 & $145,55 \pm 2,83$ & \\
\hline & & 3 & $180,00 \pm 7,77$ & \\
\hline \multirow{3}{*}{$\begin{array}{c}\text { Speed post impact- } \\
\text { Trial No. } 2\end{array}$} & \multirow{3}{*}{2} & 1 & $98,10 \pm 10,34$ & \multirow{3}{*}{$137,24^{*}$} \\
\hline & & 2 & $143,75 \pm 5,90$ & \\
\hline & & 3 & $189,00 \pm 6,23$ & \\
\hline \multirow{3}{*}{$\begin{array}{c}\text { Speed post impact - } \\
\text { Trial No. } 3\end{array}$} & \multirow{3}{*}{2} & 1 & $97,20 \pm 6,57$ & \multirow{3}{*}{$326,96^{*}$} \\
\hline & & 2 & $144,50 \pm 3,03$ & \\
\hline & & 3 & $186,30 \pm 4,62$ & \\
\hline
\end{tabular}

Each two-way ANOVA was followed by post-hoc analysis. Significant interaction was found only among first $(\mathrm{ITN}=9)$ and second group $(\mathrm{ITN}=6)$ with the third $(\mathrm{ITN}=3)$ for $\theta_{\mathrm{K}}{ }^{*}$ and $\mathrm{H}_{\mathrm{B}}$. The variable $\mathrm{H}_{\mathrm{B}}$ showed a significant interaction among all three groups.

\section{DISCUSSION}

Several interesting outcomes were obtained from the results of statistical test. In according to previous work we founded that $\mathrm{H}_{\mathrm{B}}$ and $\mathrm{S}_{\mathrm{B}}$ are useful parameters to assess the proficiency of serve action [11]. As showed in $[8,14]$ the performance of advanced players are higher than intermediate and beginners performance outcomes. Our 
two-way ANOVA post-hoc test showed also that differences among $B$ and $I$ is not statistically meaningful for $\theta_{K}{ }^{*}$ and $H_{B}$ while differences among three groups are statistically meaningful only for $\mathrm{S}_{\mathrm{B}}$. Moreover the mean $\mathrm{S}_{\mathrm{B}}$ value in $\mathrm{I}$ and $E\left(146,45 \mathrm{~km}^{*} \mathrm{~h}^{-1}\right.$ and $\left.184,65 \mathrm{~km}^{*} \mathrm{~h}^{-1}\right)$ is in agreement $\left(145 \mathrm{~km}^{*} \mathrm{~h}^{-1}\right.$ and $\left.180 \mathrm{~km}^{*} \mathrm{~h}^{-1}\right)$ with previous result showed by $[8,9,15]$. The AP performance is also in agreement with the mean value recorded during 2000 tennis singles [11]. The correlation analyses among athletes' characteristics and performance outcomes revealed interesting information. We found a very strong correlation among ITN classification and POs. In detail the correlation was negative with the angle size $(\mathrm{r}=-.919 \mathrm{p}<0.01)$, infect the best tennis player $(I T N=3)$ flexed their knee more than other players. The correlation values of ITN rank with other POs were positive. The same trend of ITN ranking was observed with the height variable $(\mathrm{r}=-.558-\mathrm{p}<0.01, \mathrm{r}=.684-\mathrm{p}<.05, \mathrm{r}=.634-$ $\mathrm{p}<0.01$ ) and the years of practice variable, which was directly related to ITN ranking. These results confirmed that physical characteristics and technique performance level represents key of efficiency in the serve action, especially in the best athletes [4]. Moreover the high level of correlation index among $\theta_{\mathrm{K}}{ }^{*}$ and other POs confirmed the importance of knee motion in tennis serve [16]. Advanced players flexed their front knee more than B and I players and it seems a better strategy to obtain flat serve more effective, in according to [16].

\section{CONCLUSION}

This study addressed the importance of proprioceptive knee joint motion during the flat serve. Results were in line with the previous study in tennis serve analysis and support the importance of lower-limb motion in the efficacy of flat serve. Trainers could use these data in order to upgrade their training program. Computer science innovation could support their works and the use of simple and free software, such as Skill Spector, unified with good camera systems, could improve the assessment of athletes performances. Future works will address the development of more complex biomechanics model in order to assess the relation among lower-limb joint motion and upper parts of body using the same low-cost approach.

\section{ACKNOWLEDGMENTS}

We wish to thank Tony Safina for data gathering and Valentina Sgrò for her assistance with manuscript preparation.

\section{REFERENCES}

[1] Y. Sun, Y. Liu and X. Zhou. "A kinematic analysis of a top 10 WTA tennis player's first serve”, in Proceeding of 30th Annual Conference of Biomechanics in Sport, pp. 253-225, Australia: Melbourne 2012.

[2] H. Brody. "Tennis Science for Tennis Players". Philadelphia: University of Pennsylvania Press, 1987.

[3] B. C. Elliott and R. Kilderry. "The Art and Science of Tennis". Philadelphia: Saunders College Publishing, p.41, 1983.

[4] A. Goktepe, E. Ak, M. Sogut, H. Karabork, and F. Korkusuz. "Joint angles during successful and unsuccessful tennis serves kinematics of tennis serve". Joint Diseases and Related Surgery, vol. 20(3), pp. 156$60,2009$.
[5] W. B. Kibler and D. Van Der Meer. Mastering the kinetic chain. In World-Class Tennis Technique, P. Roetert and J. Groppel, Eds. Champaign, IL: Human Kinetics, pp. 99-113, 2001.

[6] R. E. Bahamonde. "Changes in angular momentum during the tennis serve”. Journal of Sport Science, vol. 18, pp. 579-592, 2000.

[7] R. E. Bahamonde. "Joint power production during flat and slice tennis serves", in Proceeding of 15th International Symposium on Biomechanics in Sports, pp. 489-494 Denton, TX, 1997.

[8] R. Bartlett, R. J. Piller and S. Miller. "A three-dimensional analysis of the tennis serves of National (British) and county standard players". In: Science and Racket Sports 1, Reilly and M.H.T.E. Lees, Eds. London: E \& FN SPON, pp. 98-102, 1995.

[9] B. C. Elliott, T. Marsh and B. Blanksby. "A three-dimensional cinematographic analysis of the tennis serve". International Journal of Sport Biomechanics, vol. 2, pp. 260-71, 1986

[10] B. C. Elliott, R. N. Marshall, and G.J. Noffal. "Contributions of upper limb segment rotations during the power serve in tennis". Journal of Applied Biomechanics, vol. 11, pp. 433-442, 1995.

[11] G. Fleisig, R. Nicholls, B.C. Elliott, and R. Escamilla. "Tennis: Kinematics used by world class tennis players to produce high - velocity serves. Sports Biomechanics, vol. 2(1), pp. 51-64, 2003.

[12] E. Sprigings, R. Marshall, B. Elliott, and L. Jennings. "A threedimensional kinematic method for determining the effectiveness of arm segment rotations in producing racquet-head speed". Journal of Biomechanics, vol. 27(3), pp. 245-254, 1994.

[13] B. Elliott, G. Fleisig, R. Nicholls, and R. Escamilia. "Technique effects on upper limb loading in the tennis serve". Journal of Science and Medicine in Sport, vol. 6(1), pp. 76-87, 2003.

[14] O. Girard, J. P. Micallef and G. P Millet. "Lower-limb activity during the power serve in tennis: effects of performance level". Med Sci Sports Exerc, vol. 37(6), pp. 1021-1029, 2005.

[15] B.C. Elliott, and G. A. Wood. "The biomechanics of the foot-up and foot-back tennis service techniques". Aust. J. Sports Sci, vol. 3, pp. 3-6, 1983 .

[16] M. Reid, B. Elliott, and J. Alderson. "Lower-limb coordination and shoulder joint mechanics in the tennis serve". Medicine+ Science in Sports+ Exercise, vol. 40(2), pp. 308, 2008.

[17] W. J. Kraemer, K. Hakkinen, N.T. Triplett-McBride, A.C. Fry, L. P. Koziris, N.A. Ratamess,... \& H.G. Knuttgen. "Physiological changes with periodized resistance training in women tennis players". Medicine and science in sports and exercise, vol. 35(1), pp. 157-168, 2003.

[18] P. Grimshaw, N. Fowler, A. Lees and A. Burden. "BIOS Instant Notes in Sport and Exercise Biomechanics". Psychology Press, 2004.

[19] C. López de Subijana Hernández and E. Navarro Cabello. "Kinetic Energy Transfer during the Serve". Biology of Sport, vol. 27(4), pp. 2-11, 2010.

[20] H. Brody, R. Cross and C. Lindsey. "The Physics and Technology of Tennis". Vista (CA): Racquet Tech Publishing, pp. 37-50, 2002.

[21] A. Lees. "Science and the major racket sports: a review". Journal of sports sciences, vol. 21(9), 707-732, 2003.

[22] J.F. Signorile, D. J Ssndler, W.N. Smith, M. Stoutenberg and A.C. Perry. "Correlation analyses and regression modeling between isokinetic testing and on-court performance in competitive adolescent tennis players". The Journal of Strength \& Conditioning Research, vol. 19(3), pp. 519-526, 2005.

[23] C. Payton and R. Bartlett. "Biomechanical Evaluation of Movement in Sport and Exercise: The British Association of Sport and Exercise Sciences Guide”. London and New York: Routledge, pp. 139, 2007.

[24] D.R. Mullineaux, R. M. Bartlett and S. Bennett. "Research design and statistics in biomechanics and motor control". Journal of Sports Sciences, vol. 19(10), pp. 739-760, 2001. 